\title{
Gestational weight gain information: seeking and sources among pregnant women
}

Jane C. Willcox ${ }^{1 *}$, Karen J. Campbell', Elizabeth A. McCarthy², Martha Lappas ${ }^{2}$ Kylie Ball', David Crawford ${ }^{1}$, Alexis Shub ${ }^{2}$ and Shelley A. Wilkinson 3,4

\begin{abstract}
Background: Promoting healthy gestational weight gain (GWG) is important for preventing obstetric and perinatal morbidity, along with obesity in both mother and child. Provision of GWG guidelines by health professionals predicts women meeting GWG guidelines. Research concerning women's GWG information sources is limited. This study assessed pregnant women's sources of GWG information and how, where and which women seek GWG information.
\end{abstract}

Methods: Consecutive women $(n=1032)$ received a mailed questionnaire after their first antenatal visit to a public maternity hospital in Melbourne, Australia. Recalled provision of GWG guidelines by doctors and midwives, recalled provided GWG goals, and the obtaining of GWG information and information sources were assessed.

Results: Participants ( $n=368 ; 35.7 \%$ response) averaged 32.5 years of age and 20.8 weeks gestation, with $33.7 \%$ speaking a language other than English. One in ten women recalled receiving GWG guidelines from doctors or midwives, of which half were consistent with Institute of Medicine guidelines. More than half the women (55.4\%) had actively sought GWG information. Nulliparous (OR 7.07, $95 \% \mathrm{Cl}=3.91-12.81)$ and obese (OR $1.96,95 \% \mathrm{Cl}=$ 1.05-3.65) women were more likely to seek information. Underweight (OR 0.29, $95 \% \mathrm{Cl}=0.09-0.97)$ women and those working part time (OR 0.52, $95 \% \mathrm{Cl}=0.28-0.97)$ were less likely to seek information. Most frequently reported GWG sources included the internet ( $82.7 \%$ ), books (55.4 \%) and friends (51.5\%). The single most important sources were identified as the internet (32.8\%), general practitioners (16.9\%) and books (14.9\%).

Conclusion: More than half of women were seeking GWG guidance and were more likely to consult non-clinician sources. The small numbers given GWG targets, and the dominance of non-clinical information sources, reinforces that an important opportunity to provide evidence based advice and guidance in the antenatal care setting is currently being missed.

Keywords: Information seeking behaviour, Pregnancy, Gestational weight gain, Weight management

\section{Background}

Achieving healthy gestational weight gain (GWG) is acknowledged as important in promoting positive maternal and fetal health outcomes in both the short and long term [1]. Weight gained in excess of GWG guidelines, termed 'excess GWG', is associated with increased prevalence of gestational diabetes, hypertensive disorders, delivery complications, large for gestational age, and the long term risk of obesity for both mother and

\footnotetext{
*Correspondence: jwillcox@deakin.edu.au

${ }^{1}$ Centre for Physical Activity and Nutrition Research, Deakin University, 221

Burwood Hwy, Burwood, Victoria 3125, Australia

Full list of author information is available at the end of the article
}

child [2-5]. The 2009 Institute of Medicine (IOM) guidelines [1] are most commonly adopted in developed countries in the absence of country specific guidelines [6] and are central to the recent refocus on GWG.

Consistent with the increased prevalence of overweight and obesity in women in their childbearing years in developed countries [7], there is also an increasing prevalence of excess GWG $[1,8]$. Between $35-60 \%$ of women, across all body mass index (BMI) categories, exceed the recommended guidelines $[2,7,9]$. Women who are overweight or obese at conception are most at risk of exceeding GWG guidelines [10]. However, women's understanding 
of appropriate GWG and the consequences for maternal and child health of excess GWG is generally poor [11]. Women view pregnancy as a time when weight is gained and may be retained or lost post-partum [11, 12].

Studies indicate that the provision of GWG guidelines by health professionals and knowledge regarding appropriate GWG is predictive of meeting GWG guidelines $[13,14]$. A recent study of 249 US women reported that having health providers offer IOM weight gain recommendations increased the likelihood of women setting a concordant GWG goal (vs. no goal) $(\mathrm{OR}=5.3,95 \% \mathrm{CI}$ : $1.5,18.6$ ), which in turn was predictive of actual weight gains that fell within IOM guidelines [14]. These findings highlight the importance of women and their health service providers identifying and understanding GWG targets.

Very little is known about GWG information seeking behaviours of women, despite pregnancy being a time of significant information seeking and knowledge acquisition for women [15]. Qualitative studies suggest that women are dissatisfied with the level of health professionals' provision of GWG information and that they may be seeking their information elsewhere $[16,17]$. Whilst it is understood that women will attain pregnancy related information from a range of sources, including books, magazines, the internet, family, friends and health professionals [18], there is currently little evidence concerning the GWG related information sources women are accessing.

The acquisition of GWG information is an important early step in achieving a healthy weight in pregnancy [19]. When planning healthy GWG interventions, a baseline understanding of potential influences on pregnant women's GWG information seeking and sources is required to allow effective targeting for knowledge and behaviour change. To our knowledge, no other studies have examined women's GWG information sources and seeking nor their demographic predictors in detail. Therefore, this study aimed to investigate pregnant women's GWG information sources and information seeking and how they varied by key demographic factors.

\section{Methods}

A cross sectional study, Pregnancy, Health, Information and You (PHIY), utilising a mailed self-administered survey was carried out at a major Australian maternity tertiary training hospital with eligibility screening between October 2012 and January 2013. The hospital did not have protocols for regular weighing or GWG counselling. The PHIY study was designed to explore GWG attitudes, knowledge and pregnancy information seeking behaviours in pregnant women at the time of their first hospital visit. The data utilised in this study were derived from the PHIY. Ethics approval was obtained from Deakin University (2012-183) and Mercy Hospital for Women (R12/29) Human Research Ethics Committees.

\section{Study population}

Consecutive eligible pregnant women were recruited from public antenatal clinic attendance registers following the woman's first hospital antenatal visit. Inclusion criteria included sufficient English to complete the survey, aged more than 18 years and continuing pregnancy care at the hospital.

\section{Recruitment}

Study packages were mailed to eligible women. The study package contained: introductory letter; pen and paper survey; plain language statement; consent form; and return stamped envelope. Participants were followed up using a protocol informed by the total design method as described by Dillman [20]. Non-responders were followed up two weeks after the initial mail-out with a reminder letter, and three weeks after the initial mail-out with a replacement questionnaire.

\section{Survey design}

The survey question development was informed by the literature and discussion with a wide range of health professionals working with pregnant women. Constructs reported in this study reflected understandings of the correlates of healthy GWG $[9,14,21]$, the predictors of health behaviours [19] and the 'uses and gratification' theory, a theory of media usage [22]. The uses and gratification theory assumes that users deliberately choose media that will satisfy a given need. The survey instrument was pilot tested for comprehensibility and clarity with a convenience sample of ten pregnant or recently pregnant women. Minor amendments were made based on this process.

The researchers did not have access to participants' email addresses and thus a hard copy mailed survey was chosen. Support for this approach is provided by literature that suggests that mailed surveys may achieve a higher response rate and produce a higher internal consistency than web or internet surveys $[23,24]$. To encourage completion of potentially sensitive information, anonymity for the surveys was guaranteed.

\section{Measures}

\section{Background characteristics}

Pregnancy characteristics assessed comprised of parity and due date. Socio-demographic variables assessed included: maternal date of birth; relationship status; country of birth; and primary language. Maternal education was categorised in three levels: completion of secondary education or less; trade/certificate or diploma; and tertiary education. Main daily activity was defined in five categories: 
working fulltime; working part time; raising children; studying fulltime; and unemployed. Per annum household income was divided into five categories: $<\$ 51,999$; $\$ 52$ 77,999; \$78-99,999; >\$99,999; and an option not to answer. Self-reported access to internet and ownership of mobile phones were dichotomous indicators of technology usage. Anthropometric questions included self-reported pre-pregnancy height and weight which were used to calculate pre-pregnancy BMI (ppBMI). BMI categories were defined based on the World Health Organization guidelines [25].

Basic demographic data, including age (as a continuous variable) and primary language, were collected from the hospital data base on all eligible women allowing comparisons between responders and non-responders.

\section{Outcome variables}

Constructs related to GWG information included:

1. GWG information seeking;

2. Information sources accessed for GWG information; and

3. Recalled GWG guideline provision by a doctor or midwife.

The latter assessed participant recall of the counselling rather than health professional report because ultimately the participant's own recall will influence weight gain and the advice provided was unavailable. Additional file 1 outlines the questions, sources and reliability testing of the questions.

Reliability testing was conducted on questions that had not been tested previously. Survey question test-retest reliability was established via repeated administration of the survey two weeks apart in a separate sample of 38 pregnant women.

\section{Sample size}

The outcome measure utilised for sample size calculations was the provision of GWG guidelines by a doctor or midwife, a dichotomous variable. A study sample of $n=360$ from a potential population of 5500 allowed estimation with $95 \%$ confidence intervals of a population proportion being provided with GWG guidelines with precision of approximately $5 \%$ and estimation of a population mean with precision of approximately $10 \%$ of the population standard deviation.

\section{Data analyses}

Analysis was conducted using Stata 12 (Stata Corp, College Station, Texas, USA). Descriptive statistics (mean, standard deviation, percent and range) were used to describe characteristics of the sample. The normality of continuous variables was assessed by visual inspection of histograms.
Statistical tests (group mean comparison $t$ test and $x^{2}$ test) were used to assess differences in characteristics between non responders and responders, identified by hospital identification number to maintain anonymity. Logistic regression was used to investigate the predictors of GWG information seeking and GWG sources nominated as the most important, controlling for technology usage. Associations between each individual characteristic (sociodemographic status, pregnancy, ppBMI and technology usage) and GWG information seeking were identified in bivariable logistic regression analyses, and only those characteristics significantly $(\mathrm{p} \leq 0.05)$ associated with outcome were adjusted for in multivariable analyses. This procedure was repeated to identify predictors for the nomination of the most important GWG information sources grouping sources into three categories of media (internet, brochures, books, blogs, magazines), health professionals and family and friends.

\section{Results}

A total of 1032 consecutive eligible women received a mailed questionnaire after their first antenatal visit. Thirty six percent of participants completed surveys that were eligible for inclusion $(n=368)$ (Fig. 1). Responders were significantly older ( 32.5 vs 31.1 years, $\mathrm{p}<0.001$ ) than the non-responders but with no significant difference reported for a primary language other than English.

\section{Participant characteristics}

The characteristics of the 368 participants are presented in Table 1. The mean age of participants was 32.5 years with a

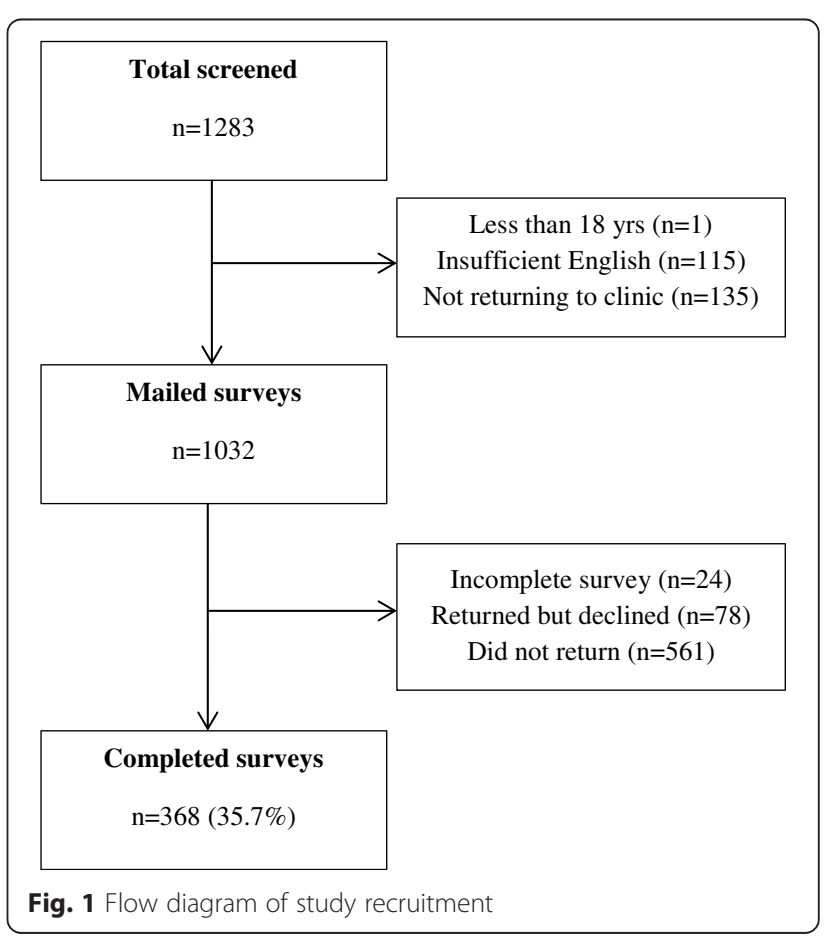


Table 1 Participant characteristics

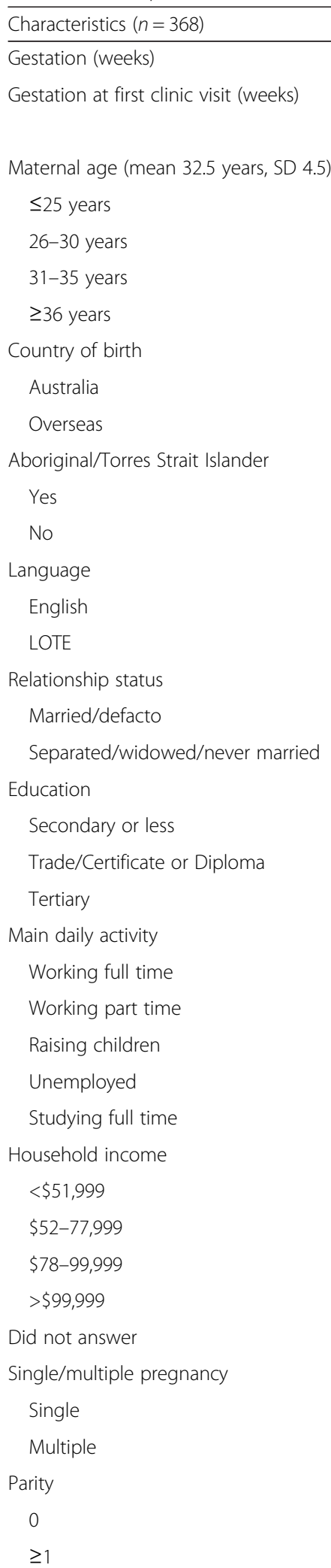

Table 1 Participant characteristics (Continued)

\begin{tabular}{ll}
\hline BMI kg/m² $($ mean $24.6, \mathrm{SD} 5.6)$ & $18(4.9)$ \\
Underweight $\left(<18.5 \mathrm{~kg} / \mathrm{m}^{2}\right)$ & $219(59.5)$ \\
Healthy weight $\left(18.5-24.9 \mathrm{~kg} / \mathrm{m}^{2}\right)$ & $75(20.4)$ \\
Overweight $\left(25-29.9 \mathrm{~kg} / \mathrm{m}^{2}\right)$ & $56(15.2)$ \\
Obese $\left(30-34.9 \mathrm{~kg} / \mathrm{m}^{2}\right)$ & \\
Use internet & $363(99.2)$ \\
Yes & $3(0.8)$ \\
No & \\
Mobile phone ownership & $362(98.6)$ \\
Yes & $5(1.4)$ \\
No & \\
\hline BMI body mass index, LOTE, language other than English, SD standard deviation
\end{tabular}

mean gestation of 20.8 weeks. Nearly one half of women were nulliparous. More than one third of women were born overseas and spoke a language other than English at home. More than half of the women had some tertiary education. Approximately one third of women reported working full time with another third working part time. More than one half reported a household income over $\$ 78,000$. The majority of participants had access to the internet and a mobile phone. Twenty percent of the women had a BMI in the overweight and $15.2 \%$ in the obese ranges.

$40(10.9)$

$101(27.5)$

$227(61.7)$

$137(37.2)$

$118(32.1)$

$92(25.0)$

$13(3.5)$

$8(2.2)$

$72(19.6)$

$64(17.4)$

72 (19.6)

109 (29.6)

51 (13.9)

$360(97.8)$

$8(2.2)$

$173(47.0)$

$195(53.0)$

\section{GWG information seeking}

More than half of the women $(n=202,54.9 \%)$ had actively sought GWG information. Table 2 presents the results of the bivariable and multivariable logistic regression analysis of GWG information seeking. In the multivariable analysis, four variables remained significant predictors of GWG information seeking. Women having their first child were seven times more likely to seek GWG information than those with subsequent pregnancies. Those with a BMI in the obese category were more than twice as likely to seek GWG information compared with women in the healthy weight range. Women nominating "working part time" as their key daily activity were half as likely to seek GWG information as those who nominated raising children fulltime. Those with a BMI in the underweight category were two thirds less likely to seek information compared with women in the healthy weight range.

\section{Recalled provision of GWG guidelines by health professionals}

Only $9.5 \%(n=35)$ of women recalled receiving GWG guidelines from doctors or midwives. Of the recalled weight guidelines given by health professionals, $54.3 \%$ $(n=19)$ were consistent with IOM GWG guidelines. The small numbers in this group precluded further analysis of predictors. 
Table 2 Odds ratios and $95 \%$ confidence intervals from bivariable and multivariable logistic regression analyses predicting GWG information seeking

\begin{tabular}{|c|c|c|c|c|c|c|c|c|}
\hline \multirow[t]{2}{*}{$n=368$} & \multicolumn{2}{|c|}{ Sought GWG information } & \multicolumn{3}{|c|}{ Bivariable associations $^{a}$} & \multicolumn{3}{|c|}{ Multivariable associations ${ }^{\mathrm{a}, \mathrm{b}}$} \\
\hline & No $(n / \%)$ & Yes $(n / \%)$ & $\overline{\mathrm{OR}}$ & $95 \% \mathrm{Cl}$ & $p$ & $\overline{\mathrm{OR}}$ & $95 \% \mathrm{Cl}$ & $p$ \\
\hline Total & 166 & 202 & & & & & & \\
\hline \multicolumn{9}{|l|}{ Maternal age } \\
\hline$\leq 30$ years & $65(39.2)$ & $97(48.0)$ & 1.00 & Ref & & 1.00 & Ref & \\
\hline $31-35$ years & $62(37.3)$ & $57(28.2)$ & 0.62 & $0.38,0.99$ & 0.05 & 1.15 & $0.64,2.07$ & 0.63 \\
\hline$\geq 36$ years & $39(23.5)$ & $48(23.8)$ & 0.83 & $0.45,1.4$ & 0.47 & 1.45 & $0.76,2.77$ & 0.26 \\
\hline \multicolumn{9}{|l|}{ Country of birth } \\
\hline Australia & $110(66.3)$ & $120(59.4)$ & 1.00 & Ref & & & & \\
\hline Overseas & $56(33.7)$ & $82(40.6)$ & 1.35 & $0.88,2.05$ & 0.18 & & & \\
\hline \multicolumn{9}{|l|}{ Language } \\
\hline English & $114(68.7)$ & $130(64.4)$ & 1.00 & Ref & & & & \\
\hline LOTE & $52(31.3)$ & $72(35.6)$ & 1.21 & $0.78,1.88$ & 0.87 & & & \\
\hline \multicolumn{9}{|l|}{ Education } \\
\hline Secondary or less & $22(13.3)$ & $18(8.9)$ & 1.00 & Ref & & & & \\
\hline Trade/Certificate/Diploma & $50(30.1)$ & $51(25.2)$ & 1.25 & $0.60,2.60$ & 0.56 & & & \\
\hline Tertiary & $94(56.6)$ & $133(65.9)$ & 1.73 & $0.88,3.40$ & 0.11 & & & \\
\hline \multicolumn{9}{|l|}{ Main daily activity } \\
\hline Working full time & $39(23.5)$ & $98(48.5)$ & 2.89 & $1.65,5.00$ & $<0.01$ & 0.79 & $0.39,1.60$ & 0.52 \\
\hline Working part time & $68(41.0)$ & $50(24.8)$ & $0.84(p<0.001)$ & $0.48,1.45$ & 0.53 & 0.52 & $0.28,0.97$ & 0.04 \\
\hline Raising children & $49(29.5)$ & $43(21.3)$ & 1.00 & Ref & & 1.00 & Ref & \\
\hline Unemployed/studying & $10(6.0)$ & $11(5.4)$ & 1.25 & $0.49,3.24$ & 0.64 & 0.40 & $0.13,1.24$ & 0.11 \\
\hline \multicolumn{9}{|l|}{ Household income } \\
\hline$<\$ 51,999$ & $37(22.3)$ & $35(17.3)$ & 1.00 & Ref & & 1.00 & Ref & \\
\hline$\$ 52-77,999$ & $34(20.5)$ & $30(14.9)$ & 0.98 & $0.52,1.83$ & 0.84 & 0.86 & $0.40,1.85$ & 0.71 \\
\hline$\$ 78-99,999$ & $37(22.3)$ & $35(17.3)$ & 1.00 & $0.52,1.91$ & 1.00 & 1.09 & $0.51,2.31$ & 0.83 \\
\hline$>\$ 99,999$ & $37(22.3)$ & $72(35.6)$ & 2.01 & $1.11,3.78$ & 0.02 & 1.96 & $0.96,4.01$ & 0.07 \\
\hline Did not answer & $21(12.6)$ & $30(14.9)$ & 1.51 & $0.73,3.12$ & 0.27 & 1.57 & $0.69,3.55$ & 0.28 \\
\hline \multicolumn{9}{|l|}{ Parity } \\
\hline 0 & $41(24.7)$ & $132(65.3)$ & 5.78 & $3.64,9.08$ & $<0.01$ & 7.07 & $3.91,12.81$ & $<0.01$ \\
\hline$\geq 1$ & $125(75.3)$ & $70(34.7)$ & 1.00 & Ref & & 1.00 & Ref & \\
\hline \multicolumn{9}{|l|}{ 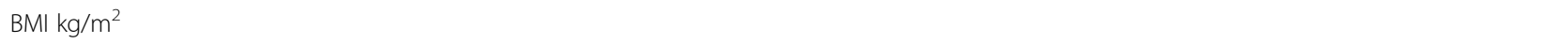 } \\
\hline Underweight $\left(<18.5 \mathrm{~kg} / \mathrm{m}^{2}\right)$ & $13(7.8)$ & $5(2.5)$ & 0.32 & $0.11,0.92$ & 0.04 & 0.29 & $0.09,0.97$ & 0.04 \\
\hline Healthy weight $\left(18.5-24.9 \mathrm{~kg} / \mathrm{m}^{2}\right)$ & $99(59.6)$ & $120(59.4)$ & 1.00 & Ref & & 1.00 & Ref & \\
\hline Overweight $(25-29.9$ kg/m²) & $37(22.3)$ & $38(18.8)$ & 0.85 & $0.50,1.43$ & 0.54 & 1.02 & $0.56,1.87$ & 0.94 \\
\hline Obese $\left(30-34.9 \mathrm{~kg} / \mathrm{m}^{2}\right)$ & $17(10.2)$ & $39(19.3)$ & 1.89 & $1.01,3.55$ & 0.05 & 2.61 & $1.23,5.33$ & 0.01 \\
\hline
\end{tabular}

Ref., reference category; LOTE, language other than English

a Analysis adjusted for access to technology

${ }^{b}$ Characteristics significantly $(p \leq 0.05)$ associated with outcome in bivariable analysis were included in multivariable analyses

\section{Sources of GWG information}

Women reported accessing multiple sources for GWG information (Table 3). The most commonly accessed sources included the internet (82.7\%), books (55.4\%), friends $(51.5 \%)$, general practitioner (GP; $44.6 \%)$ and family $(43.1 \%)$. When asked to nominate their most important source of GWG information one third of women cited the internet as their most important source (32.8\%) followed by GPs (16.9\%), books (14.9\%) and obstetricians (12.3\%).

Further analysis was conducted on the two groups of women choosing health professionals or media (internet, brochures, books, blog, magazines) as their most important source of information regarding GWG. The small 
Table 3 Sources of GWG information

\begin{tabular}{|c|c|c|}
\hline $\begin{array}{l}\text { Source of GWG information } \\
(n=202)\end{array}$ & $\begin{array}{l}\text { Sources accessed } \\
(n / \%)\end{array}$ & $\begin{array}{l}\text { Single most important } \\
\text { source }^{b}(n / \%)\end{array}$ \\
\hline Internet & 167 (82.7) & $64(32.8)$ \\
\hline Books & $112(55.4)$ & $29(14.9)$ \\
\hline Friends & $104(51.5)$ & $9(4.6)$ \\
\hline GP & $90(44.6)$ & $33(16.9)$ \\
\hline Family & $87(43.1)$ & $4(2.1)$ \\
\hline Magazines & 74 (36.6) & $3(1.5)$ \\
\hline Midwife & $58(28.7)$ & $15(7.7)$ \\
\hline Obstetrician & $51(25.2)$ & $24(12.3)$ \\
\hline Chat/blog & $32(15.8)$ & $2(1.0)$ \\
\hline Brochures & $30(14.9)$ & $3(1.5)$ \\
\hline Dietitian & $20(9.9)$ & $8(4.1)$ \\
\hline Social media & $10(5.0)$ & \\
\hline TV/Radio & $7(3.5)$ & \\
\hline Other & $6(3.0)$ & $1(0.5)$ \\
\hline Naturopath & $2(1.0)$ & \\
\hline Pharmacist & $2(1.0)$ & \\
\hline
\end{tabular}

$G P$, General Practitioner or primary care physician

${ }^{\mathrm{a}}$ Multiple sources allowed

${ }^{\mathrm{b}} n=195$ responses

numbers choosing family and friends precluded analyses. Table 4 presents the results of the bivariable and multivariable logistic regression analyses predicting the choice of health professionals or media as the most important source utilising health professionals as the reference category. After controlling for the two significant bivariable variables in the multivariable analysis, country of birth remained the only significant predictor. Women born in a country other than Australia were three times more likely than those born in Australia to view media sources as the most important GWG information source.

\section{Discussion}

This study showed that in this sample of women attending a public maternity hospital, more women were likely to seek GWG information than be offered GWG guidelines by health professionals. The small numbers $(9.5 \%)$ provided with GWG guidelines and with evidence based guidelines $(5.2 \%)$ was lower than figures reported in similar studies [16]. For example, a recent study of practitioner provision of healthy GWG advice to 310 Canadian women reported that $28.5 \%$ of women were counselled correctly by their health care providers about GWG [16]. While it must be acknowledged that reported provision of GWG guidelines from health professionals was unavailable, the small numbers of women recalling guidelines in the present study is concerning given evidence suggesting that provision of guidelines increases the likelihood of women setting a concordant GWG goal and gaining weight consistent with the guidelines [14].

The low rate of guideline provision reported in this study may be at least partly attributable to the cross sectional study design. Surveying women at various time points across pregnancy may have produced different results given that information requirements may potentially change over the course of pregnancy. Moreover, health professionals often raise issues when a problem is noted [26]. Conversely, the average gestation of women completing the study was 20.8 weeks and women would likely have attended a minimum of two health professional visits, one with their general practitioner in the community and one at the antenatal clinic, and most likely more. That the majority of women, more than half way through their gestation, have not recalled receiving GWG guidelines raises concern and signals opportunities for earlier discussion of GWG.

Recent studies of general practitioners, obstetricians and midwives demonstrate a range of views and practices regarding GWG, with less than one third of these health professionals providing GWG guidelines and many exhibiting limited understanding of the clinical significance of excess GWG [27-30]. This may be in part explained by absence of GWG and weighing protocols, limited time for consultations for discussion of multiple antenatal issues, low awareness of guidelines for weighing and GWG, limited education regarding GWG, low levels of confidence and changes in clinical guidelines and practice resulting in non-evidence based approaches to care and advice [27-30]. New models of care that promote health professionals' discussion and implementation of GWG monitoring and guidelines are required. Parallels may be drawn from the smoking cessation literature where combining evidence based guidelines with an implementation program addressing health professional barriers resulted in an increase in evidence-based practice with some indication of improved smoking behaviour for women [31].

Pregnancy is a time of significant information seeking and knowledge acquisition $[15,26]$ and therefore it is not unexpected that more than half the women $(55.4 \%)$ had actively sought GWG information. This study found that first-time mothers were seven times more likely to seek GWG information than those with subsequent pregnancies. Women are more likely to rely on their own experience in subsequent pregnancies [32]. Pregnancy is one of the few life transition points where the majority of women are interested in their health and actively seek information with the health of their baby as the central focus [26]. Given that first time mothers, in particular, are seeking GWG information this phase of life offers opportunities to influence their future health and health behaviours, in addition to subsequent pregnancy weight gains. 
Table 4 Odds ratios and $95 \%$ confidence intervals from bivariable and multivariable logistic regression analysis predicting use of health professionals or media as the most important GWG source ${ }^{a}$

\begin{tabular}{|c|c|c|c|c|c|c|c|c|}
\hline \multirow[t]{2}{*}{$n=181$} & \multicolumn{2}{|c|}{ Sought GWG information } & \multicolumn{3}{|c|}{ Bivariate associations $^{\mathrm{b}}$} & \multicolumn{3}{|c|}{ Multivariate associations ${ }^{\mathrm{b}, \mathrm{c}}$} \\
\hline & Health prof (n/\%) & Media $(n / \%)$ & $\overline{\mathrm{OR}}$ & $95 \% \mathrm{Cl}$ & $p$ & $\overline{\mathrm{OR}}$ & $95 \% \mathrm{Cl}$ & $p$ \\
\hline Total & 80 & 101 & & & & & & \\
\hline \multicolumn{9}{|l|}{ Maternal age } \\
\hline$\leq 30$ years & $35(43.7)$ & $55(54.5)$ & 1.00 & Ref & & & & \\
\hline $31-35$ years & $23(28.8)$ & $27(26.7)$ & 0.75 & $0.37,1.50$ & 0.41 & & & \\
\hline$\geq 36$ years & $22(27.5)$ & 19 (18.8) & 0.83 & $0.26,1.16$ & 0.12 & & & \\
\hline \multicolumn{9}{|l|}{ Country of birth } \\
\hline Australia & $59(73.8)$ & $48(47.5)$ & 1.00 & Ref & & 1.00 & Ref & \\
\hline Overseas & $21(26.2)$ & $53(52.5)$ & 3.10 & $1.65,5.84$ & $<0.01$ & 3.20 & $1.76,6.85$ & $<0.01$ \\
\hline \multicolumn{9}{|l|}{ Language } \\
\hline English & $58(72.5)$ & $60(59.4)$ & 1.00 & Ref & & & & \\
\hline LOTE & $22(27.5)$ & $41(40.6)$ & 1.80 & $0.96,3.39$ & 0.07 & & & \\
\hline \multicolumn{9}{|l|}{ Education } \\
\hline Secondary or less & $9(11.2)$ & $6(5.9)$ & 1.00 & Ref & & & & \\
\hline Trade/Certificate Diploma & $17(21.3)$ & $28(27.7)$ & 2.47 & $0.75,8.17$ & 0.14 & & & \\
\hline Tertiary & $54(67.5)$ & $67(66.3)$ & 1.73 & $0.88,3.40$ & 0.28 & & & \\
\hline \multicolumn{9}{|l|}{ Main daily activity } \\
\hline Working full time & $35(43.7)$ & $52(51.5)$ & 0.69 & $0.31,1.51$ & 0.34 & 1.02 & $0.44,2.37$ & 0.96 \\
\hline Working part time & 27 (33.8) & $17(16.8)$ & 0.29 & $0.12,0.72$ & 0.01 & 0.40 & $0.16,1.03$ & 0.06 \\
\hline Raising children & $13(16.3)$ & $28(27.7)$ & 1.00 & Ref & & 1.00 & Ref & \\
\hline Unemployed/studying & $5(6.2)$ & $4(4.0)$ & 0.37 & $0.09,1.62$ & 0.19 & 0.34 & $0.07,1.57$ & 0.17 \\
\hline \multicolumn{9}{|l|}{ Household income } \\
\hline$<\$ 51,999$ & $12(15.0)$ & $17(16.8)$ & 1.00 & Ref & & & & \\
\hline$\$ 52-77,999$ & $11(13.8)$ & $17(16.8)$ & 1.10 & $0.38,3.15$ & 0.87 & & & \\
\hline$\$ 78-99,999$ & $13(16.3)$ & $18(17.8)$ & 0.98 & $0.35,2.73$ & 0.97 & & & \\
\hline$>\$ 99,999$ & $29(36.2)$ & $37(12.9)$ & 0.90 & $0.38,2.12$ & 0.82 & & & \\
\hline Did not answer & $15(18.7)$ & $12(11.8)$ & 0.56 & $0.20,1.63$ & 0.29 & & & \\
\hline \multicolumn{9}{|l|}{ Parity } \\
\hline 0 & $49(61.3)$ & $70(69.3)$ & 1.43 & $0.77,2.65$ & 0.26 & & & \\
\hline$\geq 1$ & $31(38.7)$ & $31(30.7)$ & 1.00 & Ref & & & & \\
\hline \multicolumn{9}{|l|}{$\mathrm{BMI} \mathrm{kg} / \mathrm{m}^{2}$} \\
\hline Underweight $\left(<18.5 \mathrm{~kg} / \mathrm{m}^{2}\right)$ & $1(1.3)$ & $3(3.0)$ & 2.11 & $0.21,21.02$ & 0.52 & & & \\
\hline Healthy weight $\left(18.5-24.9 \mathrm{~kg} / \mathrm{m}^{2}\right)$ & $43(53.8)$ & $61(60.4)$ & 1.00 & Ref & & & & \\
\hline Overweight $\left(25-29.9 \mathrm{~kg} / \mathrm{m}^{2}\right)$ & $13(16.2)$ & $21(20.8)$ & 1.14 & $0.51,2.52$ & 0.75 & & & \\
\hline Obese $\left(30-34.9 \mathrm{~kg} / \mathrm{m}^{2}\right)$ & $23(28.7)$ & $16(15.8)$ & 0.49 & $0.23,1.04$ & 0.06 & & & \\
\hline
\end{tabular}

Ref. reference category, LOTE language other than English

a Reference category - health professional

${ }^{b}$ Analysis adjusted for access to technology

c Characteristics significantly $(\mathrm{p} \leq 0.05)$ associated with outcome in bivariable analysis were included in multivariable analyses

It is positive to note that women who were obese at conception were more likely to seek GWG information given that this group is at greater risk of exceeding GWG guidelines than those who are not obese [10]. This is in line with non-pregnancy literature suggesting that people identifying as overweight or obese had a higher level of weight concern [33]. Relatedly, a thematic analysis of 400 posts made in a UK-based parenting internet forum suggested that overweight women were concerned about the impact of their weight on the growing baby [34]. Further exploration of women's motivations to seek information, taking into account their pre-pregnancy BMI, their GWG 
goals and subsequent GWG could offer insights into future models to promote healthy GWG in this high risk group.

Recent literature on information seeking in pregnancy has focused on the use of electronic media, for example the internet, as the growing and most often utilised information source [35-37]. While the vast majority of women in this study used the internet to find GWG information, and many nominated it as the most important source, women, on average, collected information from more than four sources. This finding is consistent with the uses and gratification theory [22], suggesting that women have power over their media and information consumption and take an active role in interpreting and integrating media into their own lives [22,38].

Of interest is the high proportion of women nominating media, compared with health professionals, as their most important source of GWG information. The wide range of media sources available allows women to obtain information in formats that are accessible, affordable and culturally and linguistically appropriate which may in part explain their preference for them. This study does not provide an insight into what GWG information is contained in media sources but general studies of the internet suggest that the information is varied and often lacks an evidence base [39]. Further, if health professionals are not providing information at point of care, women maybe more likely to seek information elsewhere with other research in pregnancy suggesting that media sources, such as internet and books, are viewed as objective and up to date sources [32]. Additionally, a recent study of 613 women from 24 countries found women expressed that their confidence levels significantly increased with respect to making decisions about their pregnancy after internet usage $(p<0.05)$ [37]. Health professionals' reluctance to engage with technology and media sources [28] may also contribute to this divide.

Women born outside Australia nominated media sources, including the internet, as their most important source compared with health professionals. This is not surprising given the high levels of technology usage by cultural and minority groups [40]. Internet use in pregnancy is associated with high levels of health literacy and self-efficacy [41] and, given the high levels of education in the sample, it may be seen as a positive indicator of women being able to find culturally and linguistically appropriate information. There is a need for health professionals to acknowledge the use of different media for information and incorporate it into pregnancy education and healthy GWG interventions providing guidance on data retrieval, interpretation, and application of credible sources.

To our knowledge this is the first study to explore women's GWG information seeking predictors and sources of GWG information in detail. While it was not the study's intention to achieve population representative data, it is useful to consider the generalisability of the sample population and hence the results. The education levels of mothers in the sample were higher than seen in other studies of young mothers or pregnant women [42]. The lower response rate achieved from low educated women is consistent with literature regarding determinants of research participation [43]. Interestingly, the study participants were more likely to be born overseas (37.6\% compared with $27 \%$ ) [44] and speak another language at home (33.9\% compared $22.2 \%$ ) [45] than the general Australian population. This is curious given past literature suggests that people from minority cultural backgrounds are less likely to participate in health related research or attend antenatal clinics [46]. This may reflect the catchment of the large maternity hospital which includes areas of high migrant populations and the open access opportunities for pregnant women at the tertiary hospital. A potential limitation of the study is the reliance on the self-reported prepregnancy weight with the potential for recall bias, and hence, biased analyses. This is a common concern for GWG studies where more detailed assessments are not considered feasible. A further limitation involves the size of the dataset for the logistic regression analysis of women's most important GWG source with the elimination of the family and friends category due to insufficient numbers. Further studies with a larger data set would allow more detailed analysis of this category.

\section{Conclusion}

This first of a kind study provides new knowledge on women's GWG information seeking and information sources. More than half of women sought GWG guidance and were more likely to consult non-clinician sources. The small numbers provided with GWG targets, and the dominance of non-clinical information sources, supports the need for GWG guidance from reputable sources. Given the high level of media usage by women, further research is required to assess the quality of content of these resources. Integration of evidence based media sources into antenatal care would augment the care of pregnant women and may serve to improve health professional and pregnant women interaction regarding healthy GWG.

\section{Additional file}

Additional file 1: GWG information seeking outcome measures.

\section{Abbreviations}

BMI: Body mass index; GWG: Gestational weight gain; ppBMI: Pre-pregnancy body mass index.

Conflicts of interest

The authors declare that they have no conflicts of interest.

\section{Authors' contributions}

JW designed the study, project managed the research and prepared the manuscript. JW and ML oversaw data collection. JW and KB conducted the statistical analysis. KJC, EAM, ML, KB, DC, AS and SAW participated in the 
research design and interpretation of the data. All authors read and approved the final manuscript.

\section{Acknowledgements}

JW is supported by a Sidney Myer Health Scholarship, SW by a Queensland Health - Health Research Fellowship, KB by a National Health and Medical Research Council (NHMRC) Principal Research Fellowship (ID 1042442) and ML by an NHMRC Career Development Fellowship (ID 1047025). The contents of this manuscript are the responsibility of the authors and do not reflect the views of the funding bodies.

The authors acknowledge the time and effort contributed by the participants and the data collection involvement of Courtney Wall.

\section{Author details}

${ }^{1}$ Centre for Physical Activity and Nutrition Research, Deakin University, 221 Burwood Hwy, Burwood, Victoria 3125, Australia. ${ }^{2}$ Department of Obstetrics and Gynaecology, University of Melbourne/Mercy Hospital for Women, Melbourne, Australia. ${ }^{3}$ Mater Research Institute, University of Queensland, South Brisbane, Queensland, Australia. ${ }^{4}$ Department of Nutrition \& Dietetics, Mater Mothers Hospital, South Brisbane, Queensland, Australia.

Received: 12 January 2015 Accepted: 24 July 2015

Published online: 07 August 2015

\section{References}

1. IOM, NRC, Rasmussen K, Yaktine A. Weight gain during pregnancy: reexamining the guidelines. Washington: The National Academies Press; 2009.

2. Mamun AA, Callaway LK, O'Callaghan MJ, Williams GM, Najman JM, Alati R, et al. Associations of maternal pre-pregnancy obesity and excess pregnancy weight gains with adverse pregnancy outcomes and length of hospital stay. BMC Preg Child. 2011;11:62

3. Jensen DM, Ovesen P, Beck-Nielsen H, Molsted-Pedersen L, Sorensen B, Vinter C, et al. Gestational weight gain and pregnancy outcomes in 481 obese glucose-tolerant women. Diabetes Care. 2005;28(9):2118-22.

4. Durie DE, Thornburg LL, Glantz JC. Effect of second-trimester and third-trimester rate of gestational weight gain on maternal and neonatal outcomes. Obstet Gynecol. 2011;118(3):569-75.

5. Mamun AA, Kinarivala M, O'Callaghan MJ, Williams GM, Najman JM, Callaway LK. Associations of excess weight gain during pregnancy with long-term maternal overweight and obesity: evidence from $21 \mathrm{y}$ postpartum follow-up. Am J Clin Nutr. 2010;91(5):1336-41.

6. Oteng-Ntim E, Varma R, Croker H, Poston L, Doyle P. Lifestyle interventions for overweight and obese pregnant women to improve pregnancy outcome: systematic review and meta-analysis. BMC Med. 2012;10(1):47.

7. Boyle A, Timofeev J, Halscott T, Desale S, Driggers RW, Ramsey PS. Is 40 the new 30?: pregnancy outcomes by degree of weight gain among obesity subclasses. Obstet Gynecol. 2014;123 Suppl 1:41S.

8. Kinnunen TI, Luoto R, Gissler M, Hemminki E. Pregnancy weight gain from 1960s to 2000 in Finland. Int J Obes Relat Metab Disord. 2003;27(12):1572-7.

9. Kowal C, Kuk J, Tamim H. Characteristics of weight gain in pregnancy among Canadian women. Matern Child Health J. 2012;16(3):668-76.

10. Weisman CS, Hillemeier MM, Downs DS, Chuang CH, Dyer A-M. Preconception predictors of weight gain during pregnancy: prospective findings from the Central Pennsylvania Women's Health Study. Womens Health Issues. 2010;20(2):126-32.

11. Groth SW, Kearney MH. Diverse women's beliefs about weight gain in pregnancy. J Midwifery Womens Health. 2009;54(6):452-7.

12. Rössner S. Pregnancy, weight cycling and weight gain in obesity. Int J Obes Relat Metab Disord. 1992;16(2):145-7.

13. Cogswell ME, Scanlon KS, Fein SB, Schieve LA. Medically advised, mother's personal target, and actual weight gain during pregnancy. Obstet Gynecol. 1999;94(4):616-22

14. Tovar A, Guthrie LB, Platek D, Stuebe A, Herring SJ, Oken E. Modifiable predictors associated with having a gestational weight gain goal. Matern Child Hlth J. 2011;15(7):1119-26.

15. Shieh C, Broome ME, Stump TE. Factors associated with health informationseeking in low-income pregnant women. Women Health. 2010;50(5):426-42.

16. McDonald SD, Pullenayegum E, Taylor VH, Lutsiv O, Bracken K, Good C, et al. Despite 2009 guidelines, few women report being counseled correctly about weight gain during pregnancy. Am J Obstet Gynecol. 2011;205(4):333. e331-336.

17. Brown A, Avery A. Healthy weight management during pregnancy: what advice and information is being provided. J Hum Nutr Diet. 2012;25(4):378-87.

18. Grimes HA, Forster DA, Newton MS. Sources of information used by women during pregnancy to meet their information needs. Midwifery. 2014;30(1):e26-33.

19. Michie S, Ashford S, Sniehotta FF, Dombrowski SU, Bishop A, French DP. A refined taxonomy of behaviour change techniques to help people change their physical activity and healthy eating behaviours: The CALO-RE taxonomy. Psychol Health. 2011;26(11):1479-98.

20. Dillman D. Mail and telephone surveys: the total design method. New York: John Wiley \& Sons, Inc.; 1978.

21. Brawarsky P, Stotland NE, Jackson RA, Fuentes-Afflick E, Escobar GJ, Rubashkin N, et al. Pre-pregnancy and pregnancy-related factors and the risk of excessive or inadequate gestational weight gain. Int J Gynae Obstet. 2005;91(2):125-31.

22. Katz E, Blumler JG, Gurevitch M. Uses and Gratifications Research. Public Opin Quart. 1973;37(4):509-23.

23. Shih $\mathrm{T}-\mathrm{H}$, Fan $\mathrm{X}$. Comparing response rates in e-mail and paper surveys: $\mathrm{A}$ meta-analysis. Educ Res Rev. 2009;4(1):26-40.

24. Rookey BD, Le L, Littlejohn M, Dillman DA. Understanding the resilience of mail-back survey methods: An analysis of 20 years of change in response rates to national park surveys. Soc Sci Res. 2012;41(6):1404-14.

25. World Health Organisation. BMI Classification http://apps.who.int/bmi/ index.jsp?introPage=intro_3.html (2006). Accessed 28 April 2015.

26. Szwajcer EM, Hiddink GJ, Maas L, Koelen MA, van Woerkum CMJ. Nutritionrelated information-seeking behaviours of women trying to conceive and pregnant women: evidence for the life course perspective. Fam Pract. 2008;25 Suppl 1:i99-i104

27. Olander EK, Atkinson L, Edmunds JK, French DP. The views of pre- and postnatal women and health professionals regarding gestational weight gain: An exploratory study. Sex Reprod Health. 2011;2(1):43-8.

28. Willcox JC, Campbell KJ, van der Pligt P, Hoban E, Pidd D, Wilkinson S Excess gestational weight gain: an exploration of midwives' views and practice. BMC Pregnancy Childbirth. 2012;12:102-13.

29. van der Pligt P, Campbell K, Willcox J, Opie J, Denney-Wilson E. Opportunities for primary and secondary prevention of excess gestational weight gain: General Practitioners' perspectives. BMC Fam Pract. 2011;12(1):124

30. Wilkinson SA, Stapleton H. Overweight and obesity in pregnancy: the evidence-practice gap in staff knowledge, attitudes and practices. Aust N Z J Obstet Gynaecol. 2012;52(6):588-92.

31. Flenady V, MacPhail J, New K, Devenish-Meares P, Smith J. Implementation of a clinical practice guideline for smoking cessation in a public antenatal care setting. Aust N Z J Obstet Gynaecol. 2008;48(6):552-8.

32. Szwajcer EM, Hiddink GJ, Koelen MA, van Woerkum CMJ. Nutrition-related information-seeking behaviours before and throughout the course of pregnancy: consequences for nutrition communication. Eur J Clin Nutr. 2005;59 Suppl 1:S57-65.

33. Wardle J, Johnson F. Weight and dieting: examining levels of weight concern in British adults. Int J Obesity. 2002;26(8):1144-9.

34. Arden M, Duxbury A, Soltani $H$. Responses to gestational weight management guidance: a thematic analysis of comments made by women in online parenting forums. BMC Pregnancy Childbirth. 2014;14(1):216.

35. Weston C, Anderson JL. Internet use in pregnancy. Brit J Midwifery. 2014:22(7):488-93.

36. Lima-Pereira P, Bermúdez-Tamayo C, Jasienska G. Use of the Internet as a source of health information amongst participants of antenatal classes. J Clin Nurs. 2012;21(3-4):322-30.

37. Lagan BM, Sinclair M, Kernohan WG. Internet use in pregnancy informs women's decision making: a web-based survey. Birth. 2010;37(2):106-15.

38. Ruggiero TE. Uses and Gratifications Theory in the 21st Century. Mass Commun Soc. 2000;3(1):3-37.

39. Eysenbach G, Powell J, Kuss O, Sa E-R. Empirical studies assessing the quality of health information for consumers on the world wide web: a systematic review. JAMA. 2002;287(20):2691-700.

40. Bennett GG, Steinberg DM, Stoute C, Lanpher M, Lane I, Askew S, et al. Electronic health (eHealth) interventions for weight management among racial/ethnic minority adults: a systematic review. Obes Rev. 2014;15 Suppl 4:146-58. 
41. Shieh C, Mays R, McDaniel A, Yu J. Health literacy and its association with the use of information sources and with barriers to information seeking in clinic-based pregnant women. Health Care Women Int. 2009;30(11):971-88.

42. Thompson MW, Nassar N, Robertson M, Shand AW. Pregnant women's knowledge of obesity and ideal weight gain in pregnancy, and health behaviours of pregnant women and their partners. Aust NZ J Obstet Gyn. 2011;51(5):460-3.

43. Turrell G, Patterson C, Oldenburg B, Gould T, Roy M-A. The socio-economic patterning of survey participation and non-response error in a multilevel study of food purchasing behaviour: area- and individual-level characteristics. Public Health Nutr. 2003;6(2):181-9.

44. Australian Bureau of Statistics. 3412.0 - Migration, Australia, 2010-11. 2012. http://www.abs.gov.au/ausstats/abs@.nsf/0/84074889D69E738CCA257A5A 00120A69?opendocument. Accessed 28 April 2015.

45. Australian Bureau of Statistics. 3301.0 - Births, Australia, 2011. 2012 http://www.abs.gov.au/ausstats/abs@.nsf/mf/3301.0. Accessed 28 April 2015.

46. Pletsch PK, Howe C, Tenney M. Recruitment of minority subjects for intervention research. J Nurs Scholars. 1995;27(3):211-5.

\section{Submit your next manuscript to BioMed Central and take full advantage of:}

- Convenient online submission

- Thorough peer review

- No space constraints or color figure charges

- Immediate publication on acceptance

- Inclusion in PubMed, CAS, Scopus and Google Scholar

- Research which is freely available for redistribution 